\section{UMA VIVÊNCIA AUTO-ORGANIZADA NA EDUCAÇÃO FÍSICA ESCOLAR EM UMA ESCOLA DE NÍVEL MÉDIO}

\author{
A SELF-ORGANIZED EXPERIENCE IN SCHOOL PHYSICAL EDUCATION \\ IN A SECONDARY SCHOOL C P
}

UNA EXPERIENCIA AUTORGANIZADA EN EDUCACIÓN FÍSICA ESCOLAR EN UNA ESCUELA DE NIVEL MEDIO C

doi) https://doi.org/10.22456/1982-8918.104275

(D) Alan Rodrigo Antunes* <alan.antunes@ifms.edu.br>
(D) Mauro Betti** <maurobettionline@gmail.com>

\begin{abstract}
*Instituto Federal de Educação, Ciência e Tecnologia de Mato Grosso do Sul. (IFMS). Três Lagoas, MS, Brasil.

**Universidade Estadual Paulista "Júlio de Mesquita Filho"(Unesp). Bauru, SP, Brasil.
\end{abstract}

Resumo: A pesquisa tem como objetivo descrever e compreender os resultados de uma intervenção em processos de ensino e aprendizagem na Educação Física em uma proposta auto-organizada, com base na Teoria da Auto-Organização de Michel Debrun. Foi caracterizada como pesquisa-ação e guiou-se por duas principais questões: por que razão e para qual fim o estudante mobiliza-se ou não frente aos conteúdos a ele apresentados? Quais os atratores e ruídos, e quais seus papéis no processo de ensino e aprendizagem? Envolveu 16 estudantes de uma escola técnica federal que frequentavam o $5^{\circ}$ período do curso técnico integrado de nível médio. Nesse cenário, os resultados do processo investigativo apontaram a emergência da mobilização na medida em que surgiram atratores e ruídos identificados no processo de ensino e aprendizagem.

Palavras chave: Educação Física. Aprendizagem. Ensino Fundamental e Médio.
Recebido em: 15-06-2020 Aprovado em: 25-10-2020 Publicado em: 09-12-2020

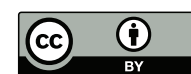

Este é um artigo publicado sob a licença Creative Commons Atribuição 4.0 Internacional (CC BY 4.0).

eISSN: $1982-8918$ 


\section{INTRODUÇÃO}

O ponto de partida desta pesquisa foi a constatação, na experiência como docente da rede pública de ensino, de que havia uma grande dificuldade dos professores em conjecturar, por um lado, os conteúdos das aulas de Educação Física e, de outro, aquilo que os estudantes traziam como experiência, como algo já vivido. Trata-se este de um problema pedagógico crucial para a Educação Física na sua condição de disciplina escolar; qual seja, a lacuna existente entre o planejamento do conteúdo pelos docentes e as perspectivas dos estudantes.

Por conseguinte, o problema de pesquisa desenhou-se considerando a hipótese de que ignorar as perspectivas e anseios dos estudantes como ponto de partida nos processos de ensino e aprendizagem impossibilitaria uma aprendizagem criativa. Tal premissa esteve atrelada ao fato de que os estudantes precisam mobilizarse para aprender, pois se não há mobilização não há ingresso na significação, o que é imprescindível para que haja aprendizagem. Nesse sentido, fez-se necessário investigar uma teoria que abarcasse em seu âmago a linguagem, a mobilização, a significação e a interação.

Com esse propósito, delineou-se um caminho de diálogo entre as ideias contidas na "Teoria da Auto-Organização", de Michel Debrun, e de forma complementar e relacional na teoria "Da Relação com o Saber", de Bernard Charlot. A partir dessas premissas, o objetivo desta pesquisa é investigar quais resultados poderiam decorrer da implementação de um processo de ensino e aprendizagem em uma proposta autoorganizada. Sendo assim, ponderam-se as perspectivas e anseios dos estudantes como um dos aspectos necessários para a mobilização, já que é principalmente a própria interação entre os envolvidos no ensino e aprendizagem que determina o resultado do processo.

Teve-se como fio condutor de todo o processo os conceitos de mobilização e atratores e ruídos. O termo "mobilização", aqui utilizado, elucida inicialmente a um conceito utilizado por Charlot $(1996,2000,2001,2005)$ ao referir-se a um movimento próprio do sujeito engajado em uma atividade originada por razões e que visam a uma meta, sendo as razões o desejo que o resultado permite satisfazer. No conceito de mobilização, Charlot (2000, p. 55-56) define móbil ${ }^{1}$ como "razão de agir", o mobilizarse é "engajar-se em uma atividade originada por móbiles" e propulsionada por eles, visando a uma meta. Charlot $(2001$, p. 55) relata que a mobilização insiste sobre a dinâmica do movimento, mobilização é colocar recursos em movimento, já que "[...] implica mobilizar-se ('de dentro'), enquanto a motivação enfatiza o fato de que se é motivado por alguém ou por algo ('de fora')". Porém, esses conceitos convergem, isto é, mobilizo-me para alcançar um objetivo, este me motiva, porém posso ser motivado por algo que poderá mobilizar-me.

Do ponto de vista educacional, tal movimento leva o sujeito em direção ao saber entrelaçado ao aprendizado como algo próprio do sujeito (embora em interação

1 Charlot (2000) refere-se a Leontiev ao discutir os conceitos de móbil e atividade. Leontiev apresenta uma perspectiva dialética destes termos: "a atividade é um conjunto de ações propulsionadas por um móbil e que visam a uma meta" (CHARLOT, 2000, p. 55). Utiliza ainda o conceito de ação: "ações são operações implementadas durante a atividade" (CHARLOT, 2000, p. 55). Neste enfoque "atividade" enfatiza "a questão dos móbiles, isto é, para ressaltar que se trata de uma atividade de um sujeito" (CHARLOT, 2000, p.56). 
com outros) e manifestado de diferentes formas. De acordo com Charlot (2000), para aprender, para ser educado, é essencial depender de si mesmo; contudo, é necessária a intermediação do outro. Nesse sentido, aprender é apropriar-se do que foi aprendido, é tornar algo seu, é "interiorizá-lo". O sujeito que aprende apropriase de uma parte do patrimônio humano que se apresenta sob formas múltiplas e heterogêneas: palavras, ideias, teorias, mas também técnicas do corpo, práticas cotidianas, gestos técnicos, formas de interações e de relações.

Atrelada a isso, a teoria da auto-organização de Michel Debrun (1996a; 1996b; 1996c) apresenta elementos conceituais chamados de atratores e ruídos, que são entendidos como o que desencadeia ou mantém a mobilização e estão imbricados com os motivos, significados e meios, o que estabelece relação com o passado, o presente e o futuro.

Os atratores são elementos que estão em comum, como o alimento, que permitem uma auto-organização em um ambiente por meio da "[...] interação dos elementos e do jogo cibernético [...]" (DEBRUN, 1996a, p. xxxix, grifo nosso). Por exemplo, o jogo cibernético², apesar de não aparecer de forma explicita no texto de Debrun (1996a), auxilia na compreensão do conceito de atrator, pois pressupõe um grande sistema de pensamento que, por meio de um novo objetivo ou uma nova meta poderá levar os elementos envolvidos no processo a modificar e a enriquecer suas experiências. Quer dizer, todos os aspectos do real são reduzidos em favor do elemento novo que aflora e que passa a ser aceito pelos elementos envolvidos.

Já o termo "ruído", que funciona como um atrator, é uma surpresa ou algo novo que surge e que, ao invés de ser destruído, é incorporado pelo sistema. Nesse sentido, os ruídos podem levar à reorganização (sucesso) de uma atividade ou à destruição (insucesso). Sendo assim, os ruídos podem "[...] intervir como provocador ou catalisador de transformações" na dinâmica interna do sistema, e/ou, incorporarse "a um processo auto-organizador como mais um dos seus elementos [...]", mas nunca como o provocador de rupturas entre os elementos envolvidos, pois nesse sentido a influência do ambiente seria maior que a própria interação entre os elementos (DEBRUN, 1996a, p. xl e xli).

Por conseguinte, identificar novidades no processo educacional só é possível na medida em que, de acordo com Shaeffer (2000, p. 16), a auto-organização é um processo com a presença de situações-problemas, nas quais os atratores e ruídos surgiriam pela própria interação e não apenas um "desenrolar trivial" sem novidades, e consequentemente sem problemas a serem resolvidos. Nesse sentido, a ampliação dos conteúdos comumente abordados nas aulas de Educação Física, como lutas, danças, ginásticas e outros esportes menos divulgados pelas mídias, mas que despertem o interesse dos estudantes, poderá proporcionar surpresas no processo educacional.

2 O conceito de "jogo cibernético" usado está no sentido da comunicação entre as pessoas. A utilização desse termo pressupõe compreender as aulas de Educação Física como um sistema que processa, reage e modifica as informações para chegar a uma forma de ensino e aprendizagem. O termo cibernético faz menção às ideias de cibernética de Norbert Wiener (mais informações sobre o autor: MASANI, Pesi R. Norbert Wiener 1894-1964. Birkhäuser, 2012), mas apenas na forma como apresenta a dinâmica de funcionamento dos sistemas.

3 Foi introduzido nos processos auto-organizativos por autores como $\mathrm{H}$. Von Forester e $\mathrm{H}$. Atlan, sendo que este último o define como: "Se, sob o impacto de perturbações aleatórias, um sistema, em vez de ser destruído ou desorganizado, reage por um acréscimo de complexidade e continua a funcionar, diremos então que o sistema é auto-organizador" (DEBRUN, 1996a, p. xi). 
Nesse ponto, a criatividade presente na teoria da auto-organização de Debrun (1996c) garante ao processo de ensino e aprendizagem situações que não seguem uma fórmula ou receita não podem ser repetidas. O envolvimento ou não envolvimento dos estudantes nas aulas de Educação Física estaria relacionado com aspectos ontológicos, culturais, sociais e epistêmicos próprios de cada sujeito, o que garantiria ao estudante o caráter humano de "exemplar único". Assim, acredita-se que a ampliação dos conteúdos tratados nas aulas de Educação Física favorece o potencial de mobilização do sujeito para a aprendizagem. Partindo do pressuposto de que a escola não é apenas uma instituição que ensina, mas que principalmente propõe aos estudantes aprenderem algo, é imprescindível considerar o estudante como agente central no processo de ensino e aprendizagem, que mobiliza e produz saberes.

Compreende-se, nesse viés de interpretação, que a auto-organização já vem sendo estudada por vários autores (SETTE, 1996; MANZOLLI; GONZALES; VERSHURE, 2000; SCHAEFFER, 2000; SILVEIRA, 2000; GONZALEZ; HASELAGER, 2002; ROMANINI, 2014) e tem como ponto convergente a natureza do pensamento criativo como uma das premissas centrais da teoria da auto-organização. Sendo assim, os atratores e ruídos, como indícios da criatividade, estão presentes no processo de ensino e aprendizagem. Nesse sentido, as novas aprendizagens surgem por meio dos atratores, por interações entre os elementos, e não de forma preestabelecida. Da mesma forma, os ruídos poderiam funcionar como provocadores de transformações, cuja efetivação aconteceria na dinâmica interna do sistema; ou como mais um dos seus elementos, porém com um impacto menor no processo já sedimentado (DEBRUN, 1996a).

O diálogo entre as ideias e conceitos de Charlot e Debrun permitiram traçar um entendimento de mobilização como um processo auto-organizado. Apresentase também um entendimento da atuação docente como uma atividade educativa que exige a produção do sujeito de si por si mesmo, mas uma autoprodução que só é possível pela interlocução com o outro em uma trama que exige o confronto dos saberes docentes com todo o contexto epistêmico, identitário, social, cultural e histórico presentes em uma aula. Ressalta-se, porém, que o elemento determinante da mobilização é a interação dos sujeitos envolvidos no processo educacional.

Diante de tal cenário e na busca de contribuir com o ensino e a aprendizagem na Educação Física, este trabalho visa compreender, a partir de uma pesquisa-ação, qual o resultado de uma intervenção no processo de ensino e aprendizagem em uma proposta auto-organizada.

\section{DELINEAMENTO METODOLÓGICO}

A pesquisa constitui-se de uma investigação da prática pedagógica, estando o pesquisador na condição de professor de Educação Física de um dos campi de uma escola técnica federal, e envolveu 16 estudantes que frequentavam o $5^{\circ}$ período do curso técnico de eletrotécnica integrado de nível médio. Buscou-se, ao implementar uma forma de trabalho com conteúdos específicos, compreender o engajamento ou 
não dos estudantes, sempre tendo em mente o desafio de considerar nas ações as perspectivas, necessidades e experiências vividas pelos estudantes como um dos elementos do ponto de partida do processo de ensino e aprendizagem.

O objetivo desta pesquisa - descrever e compreender os resultados de uma intervenção no processo de ensino e aprendizagem em uma proposta auto-organizada - leva em conta a hipótese de que os conteúdos escolares podem funcionar como atratores ou como ruídos nas aulas, o que pode levar ou não à mobilização em direção ao aprendizado dos conteúdos propostos. Considera ainda que o estudante seja capaz de aprender por meio de interações provocadoras de novas aprendizagens.

Assim, esta investigação teve como foco central as seguintes questões norteadoras: (i) Por que razão e para qual fim o estudante mobiliza-se ou não frente aos conteúdos a ele apresentados? e (ii) Quais os atratores e ruídos envolvidos, e quais seus papéis no processo de ensino e aprendizagem? Tais questões guiarão a descrição e a análise do processo de ensino e aprendizagem, de modo a melhor compreender como se dá a conexão entre os estudantes e os saberes da Educação Física.

Foram sujeitos da pesquisa 16 estudantes do $5^{\circ}$ período do curso de Informática (I5), com idade entre 15 e 17 anos, que frequentavam os cursos médios técnicos integrados oferecidos no campus onde aconteceu a pesquisa durante um bimestre do ano letivo.

Sendo assim, como o pesquisador também é docente responsável pelas turmas participantes da pesquisa, caracteriza-se a existência de um "professorinvestigador" envolvido em uma pesquisa-ação. Apesar da pesquisa-ação no domínio das pesquisas educacionais ter sido satisfatoriamente colocada à prova pelo meio científico e ter colaborado de forma significativa com estudos empíricos, a investigação nos termos da auto-organização (DEBRUN, 1996a; 1996b; 1996c) pode enriquecê-la nos sentidos epistemológico e procedimental, já que os diversos métodos de pesquisa utilizam os mesmos princípios do raciocínio lógico descritos pelo autor. Tanto a pesquisa-ação quanto a auto-organização buscam, por meio da investigação, atribuir significados aos dados coletados pela observação, de tal forma que a investigação científica permita implementar uma forma de trabalho que possa analisar os dados de maneira não apenas dedutiva, mas por descoberta, conduzida por problemas atrelados às necessidades e novidades apontadas pelos estudantes dentro do processo de ensino e aprendizagem.

A perspectiva auto-organizada apresentada realizou-se por meio de um diálogo teórico-metodológico com as diretrizes e práticas da pesquisa-ação, o qual permeou a experiência como docente desde a formação profissional e acadêmica, passando pela autoformação, até a reflexão continuada da prática pedagógica.

Tal dinâmica permitiu, pouco a pouco, avaliar e reavaliar a prática docente. Neste contexto, o professor-pesquisador busca testar na prática docente hipóteses decorrentes de problematizações e teorizações de elaboração própria. Assim, o delineamento metodológico desta investigação identifica-se com o entendimento de Stenhouse (1993, p.28), para quem "[...] a investigação é uma indagação sistemática 
e autocrítica [...]", que compreende uma curiosidade estável e não transitória, permeada por estratégias sobre hipóteses próprias e não apenas de respostas já alcançadas e prontas.

Sendo assim, uma investigação auto-organizada parte de algum tipo de problema ou surpresa, que nasce da própria dinâmica do jogo entre os elementos envolvidos no processo educacional. Contudo, na geração dos dados, obtidos durante o primeiro semestre de 2015, buscou-se evitar o chamado "efeito espelho" (ou seja, induzir os sujeitos da pesquisa a responderem aquilo que acreditam ser o esperado pelo pesquisador), quando da operação das estratégias de registros das aulas, no grupo focal (que contou com a presença de observador crítico) e nos roteiros do questionário e das entrevistas.

As estratégias de geração de dados foram usadas em três momentos da pesquisa, denominadas primeiro movimento, segundo movimento e terceiro movimento. No primeiro movimento, como ponto de partida, buscaram-se dados das experiências anteriores como docente para planejar as ações educacionais. No segundo movimento, agora com a participação dos estudantes, houve a busca de dados por meio de avaliações diagnósticas para desenvolver os conteúdos propostos por meio das ações educacionais. E o terceiro movimento constituiu-se em um exercício de investigação científica que buscou identificar as ambiguidades entre a figura do professor e a figura do investigador ou pesquisador.

Nesse viés, os resultados poderiam não satisfazer à figura do professor, mas poderiam ser ricos para o pesquisador, e assim levar à reavaliação das metodologias e aspirações teóricas utilizadas, de tal forma que as certezas poderiam ser abaladas e modificadas ou, pelo menos, contribuir para uma reflexão continuada sobre a ação docente.

Portanto, as estratégias de geração de dados e a análise dos dados foram utilizadas buscando adequação entre os objetivos e as fases da pesquisa.

\section{RESULTADOS E DISCUSSÃO}

O primeiro movimento teve como objetivo planejar a apresentação do conteúdo aos estudantes, de tal forma que permitisse a familiarização com o novo conteúdo propiciando agir no campo da prática e investigar a respeito dela. Vale ressaltar que o planejamento iniciou-se antes das aulas e continuou após cada aula, pois o método de pesquisa-ação escolhido pressupunha estudar os fatos para se buscar, a partir deles, elementos objetivos que os explicassem em uma trajetória de tentativas continuadas, sistemáticas e empiricamente fundamentadas, a fim de aprimorar a prática (TRIPP, 2005, p. 443).

Por conseguinte, os elementos objetivos estariam relacionados ao surgimento do pensamento criativo, isto é, razões do agir compreendidas como atratores ou ruídos durante as aulas, não predeterminados ou imaginados antes da vivência dos conteúdos, já que não se buscava comprovar as teorias já estabelecidas (DEBRUN, 1996b; CHARLOT, 2000), mas contribuir com uma metodologia de pesquisa adequada, inerente à prática pedagógica. 
No segundo movimento, o jiu-jítsu foi eleito como conteúdo da Educação Física. O planejamento inicial previa o caratê para a turma de estudantes em questão, porém a dinâmica das aulas, a trama do processo de ensino e aprendizagem levou à modificação. Propôs-se então aos estudantes uma escolha democrática em relação ao conteúdo, delimitada, porém, ao campo das Lutas, e realizou-se a votação considerando as três opções levantadas pelos estudantes: caratê, jiu-jítsu e boxe. Tal procedimento contribuiu para a divisão de responsabilidades, o que foi um ponto positivo para o potencial inicial de mobilização, já que esse acordo foi respeitado no decorrer das aulas.

Por certo, o formato da aula, sob o ponto de vista da auto-organização descrita por Debrun (1996b), caracterizou-se então por um ajuste mais do que um equilíbrio de forças entre o professor e os estudantes, numa relação de interdependência e dependência.

Por meio do exame do que foi apresentado durante a aula, aceitou-se como verdade que havia uma necessidade, apontada pelos estudantes, de participar da escolha do conteúdo, e de que a votação seria a melhor opção. Logo, ao aceitar a votação como meio para escolher o conteúdo a ser trabalhado, percebeu-se que não se tratava de uma simples votação, mas de um "acordo democrático" entre os envolvidos no processo de ensino e aprendizagem.

Ao estabelecer o critério de voto, mesmo sendo proposto pelo professor, foi respeitado o contexto escolar, pois é comum na instituição que os estudantes realizem "votação" para tomarem decisões relativas a várias situações. Esse impulso inicial, por ser uma decisão de todos os envolvidos, apresenta um duplo papel. Segundo Debrun (1996c), de um lado, constituiu um corte em relação ao passado e ao contexto - a partir da decisão coletiva de incluir o jiu-jítsu nas aulas -, e de outro, surge um novo contexto, novas perspectivas, ou seja, esse corte aponta, também, para o futuro. Contudo, esse impulso inicial garantiu o aspecto, nos termos de Debrun (1996b), do "auto" de uma auto-organização, o que o autor denomina de ponto de amarração.

Por conseguinte, a possibilidade de escolha das atividades a serem aprendidas consolidou-se como um atrator, já que no decorrer das aulas o acordo democrático foi respeitado e contribuiu para a interação dos estudantes em torno da aprendizagem do jiu-jítsu.

Em seguida, deu-se continuidade ao planejamento do conteúdo jiu-jítsu, por meio do levantamento das principais características do esporte nos diversos tipos de linguagem: história, técnica, aspectos culturais, influência do Mixed Martial Arts (MMA).

Além disso, para a escolha dos golpes, lançou-se mão das experiências anteriores do professor, bem como de um estudante, chamado Gabriel (considerado como elemento externo), que havia participado dos Jogos Escolares na modalidade de judô, o que foi exitoso, pois são lutas "irmãs". Diante disso, foram selecionados golpes e movimentos de fácil execução para iniciantes: i) Rolamento frontal ou rolamento lateral; ii) Rolamento para trás lateral ou rolamento para trás com auxílio; iii) Rolamento com queda lateral; iv) Chave de braço ou Armlock; v) Kimura; vi) Mataleão; vii) Montada; viii) Triângulo; e ix) Joelho na Barriga. 
Na sequência foi apresentada aos estudantes a proposta inicial para trabalhar com o conteúdo jiu-jítsu, e realizou-se uma avaliação diagnóstica, denominada "O que você sabe sobre o jiu-jítsu?", que apresentava as seguintes perguntas aos estudantes: i) Você já praticou ou conhece a luta jiu-jítsu? Explique; ii) Você sabe como surgiu o jiu-jítsu ou quem foi seu idealizador? Explique; iii) Você sabe o significado da palavra jiu-jítsu ou tem alguma ideia do que ela possa representar? Explique; iv) O que você vier a aprender nas aulas de jiu-jítsu poderá ser útil em sua vida? De que forma? v) Onde o jiu-jítsu está presente?

A atividade buscava minimizar possíveis limitações da linguagem devido aos códigos institucionalizados. E a própria estruturação da atividade continha, além das cinco perguntas, também imagens dos golpes do jiu-jítsu, o que permitiu uma familiarização por meio do contato dos estudantes com os signos/conteúdos das aulas. As impressões sobre as imagens que os estudantes poderiam apresentar são inúmeras e relacionam-se com: i) uma potencialidade de uma impressão sígnica imediata, como um pré-signo, antes das impressões serem individualizadas pelos estudantes; ii) uma interpretação como uma técnica possível de ser realizada; ou iii) como uma ideia geral culturalmente convencionada no mundo das lutas.

Buscava-se um entendimento da perspectiva dos estudantes quanto ao alcance da luta jiu-jítsu, e as respostas indicaram que a maioria dos estudantes tinha alguma ideia ou levantava hipóteses a respeito da origem da luta (como oriundas de países orientais, por exemplo, o caratê), além de relacionarem as imagens a golpes convencionados no ambiente dessa luta, como o golpe mata-leão. Tais relações, mais a característica de "novidade" do conteúdo, indicavam que haveria possibilidade desses estudantes relacionarem as explicações do professor, falas e procedimentos aos seus conhecimentos prévios.

Contudo, o jiu-jítsu, apesar de ser conhecido por quase todos os estudantes, carecia de um saber mais aprofundado, e buscava-se, além da familiarização com o conteúdo, mostrar aos estudantes que o que se aprende na Educação Física apresenta diferenças - mas não necessariamente oposição - com o que se aprende fora da escola, e que o processo de ensino e aprendizagem percorre um caminho que envolve aprender "coisas" que não conheciam ou analisar "coisas" que já sabiam, e para isso precisam atribuir sentido por meio de um conjunto de vivências que se inicia com a avaliação diagnóstica.

Portanto, para o segundo movimento considerou-se a hipótese de que o conteúdo poderia mobilizar os estudantes, pois no desenvolvimento das aulas, em uma visão auto-organizada, os estudantes já saberiam algumas coisas sobre o jiu-jítsu, mas não outras, e fariam projeções sobre o conteúdo. Ademais, havia o "acordo democrático", ou seja, a possibilidade de potencializar a mobilização ao estimular projeções dos conteúdos pela avaliação diagnóstica. Assim, seria esta uma ferramenta pedagógica e não simplesmente uma etapa burocrática do ensino.

$\mathrm{Na}$ vivência das aulas, observou-se que alguns estudantes conseguiam realizar a atividade proposta, e que eles tentavam ajudar os demais. Percebeu-se que alguns estudantes se sentiam mais à vontade com os amigos do que com o professor; outros preferiam a presença do professor, não aceitando o auxílio dos 
colegas. Essa constatação encontra guarida em um dos aspectos do processo autoorganizador apontado por Debrun (1996a, p. xxxix), no qual o sujeito tem "[...] de se integrar ao processo, de se fazer solicitante e não mandante em relação a outras partes $[\ldots] "$.

Essa estratégia permitiu a formação do que se denominou "miniambiente de aprendizagem" e fez com que os estudantes se tornassem protagonistas do próprio processo de ensino e aprendizagem. Esses "miniambientes de aprendizagem" consolidaram-se como atratores, pois surgiu por meio "[...] da interação dos elementos e do 'jogo cibernético' circular, entre as antecipações do futuro imediato e a memória do passado imediato [...]" (DEBRUN, 1996a, p. xxxix), e esteve presente em todas as aulas.

O entendimento de "jogo cibernético" auxilia na compreensão dos "miniambientes de aprendizagem" como atratores, pois um novo objetivo ou uma nova meta levou os estudantes envolvidos no processo a modificar e enriquecer suas experiências, ou seja, todos os aspectos do real foram reduzidos em favor do elemento novo que aflorou e que passou a ser aceito pelo grupo. Assim sendo, todo esse processo pondera um ir e vir "[...] que suscitam atratores provisórios e em seguida os desmancham" (DEBRUN, 1996a, p. xxxix). Atrelada a isso, tem-se a potencialidade de aparecer um atrator definitivo, ou seja, o atrator não é apresentado de antemão.

Para os demais golpes, a dinâmica continuou a mesma e com o objetivo de auxiliar na realização dos movimentos durante as aulas. Houve o elemento externo praticante de judô - que atuou tanto na preparação das aulas (como relatado) quanto durante as aulas, e vale ressaltar que foi bem aceito pela turma e atuou como um ruído no processo de ensino e aprendizagem.

Nesse sentido, a aula, ao sofrer impactos de perturbações, em vez de ser prejudicada ou desorganizada, reagiu por um acréscimo de complexidade e continuou em seu fluxo. Sendo assim, como relata Debrun (1996a, p. xi), o elemento externo pode intervir em dois papéis: "i) como modelo, havendo cumplicidade e orientação, em vez de domínio ou controle; e ii) com mais um elemento que se incorporou ao processo auto-organizador". Portanto, o estudante Gabriel, como um elemento incorporado, atuou como referência para o ensino e aprendizagem dos golpes, e ao longo das aulas não foi visto mais como um estranho, mas sim como um elemento com sentimento de pertença ao próprio grupo.

Além do estudante como elemento externo, houve a proposta de uma estudante em trazer uma amiga praticante de jiu-jítsu para auxiliar durante as aulas e compartilhar conhecimentos.

Essa iniciativa foi fundamental para o progresso das aulas, pois ela destacou uma questão muito importante sobre a prática do jiu-jítsu entre os sexos, percebido no grupo focal:

\footnotetext{
Professor: Qual foi a maior dificuldade que vocês tiveram até então com as aulas de jiu-jítsu?

EK: Para mim, foi ter que abraçar homem. Só no começo, depois vi que não tinha nada a ver!
} 
EB: Verdade, professor, mas é um pouco estranho. A gente fica com um pouco de vergonha de agarrar outro homem. Professor: E para as meninas?

EJ: Normal, é só uma luta. Mas prefiro fazer com menina e não com menino! Não cai bem, e outra coisa, tinha a Barbara e a Carla para ajudar (Grupo Focal I, 06/03/2015).

Essa "vergonha" e o "não cair bem", mesmo presentes tanto para o sexo feminino quanto para o masculino, não impediram o envolvimento dos estudantes na aula. E foi possível perceber que o novo elemento externo (do sexo feminino) também atuou como ruído e teve o papel - juntamente como o outro elemento externo (do sexo masculino) - de "ponte de ligação" entre o professor, o saber e os estudantes; isto é, atuaram como modelo/referência, e ao longo das aulas tornaram-se elementos aceitos pelo grupo.

Contudo, mesmo usando tal denominação para indicar os estudantes que não eram da turma, no decorrer das aulas deixaram de ser "externos" e passaram a fazer parte do grupo, como elemento tão importante quanto os outros. Isso aconteceu pelo fato de terem sido aceitos pelo grupo, o que foi constatado tanto na fala quanto na intencionalidade dos atos durante as aulas, bem como nos grupos focais, já que internalizaram os propósitos do grupo:

EB: Foi bacana a presença dela [elemento externo], parecia aluna da turma! E deu confiança pra gente!

ED: Verdade, era estudante do IF de tão próxima da gente!

EG: Legal que tinham eles [elementos externos], e além do senhor os dois também ajudavam e depois a gente se ajudava mesmo tendo aprendido com as aulas.

EZ: É verdade! A gente aprende e já ensina, do nosso jeito, mas o professor está aqui.

EK: É, mais esse negócio de ensinar é só junto do professor, jiu-jítsu machuca, viu! (Grupo Focal II, 07/04/2015)

Por conseguinte, percebia-se a mobilização dos estudantes, já que foi possível identificar vários atratores, e percebia-se um espírito coletivo muito forte. Por analogia, se havia atratores em concordância com as aulas, consolidava-se a interação entre os elementos envolvidos. Em concordância com tal constatação, foi possível identificar o surgimento de outros atratores, como o da proposição da realização de simulação de lutas pelos próprios estudantes, o que foi bem aceito pelo grupo e consolidou-se ao longo das aulas.

No que diz respeito a esse atrator, simulação de luta, ficou claro que, durante as aulas, foi recorrente os estudantes observarem os demais colegas realizando as atividades propostas para depois se aventurarem nas vivências. Nessa observação realizada pelos estudantes, a linguagem corporal permitiu desvelar uma intencionalidade, qual seja, um modo de analisar o real antes de investir energia (os recursos que possuem).

Esse comportamento/atitude de observação também foi identificado no grupo focal, pois mesmo os estudantes com mais dificuldades realizam as atividades propostas: 


$$
\begin{aligned}
& \text { EX: Olho e depois procuro fazer, professor, pois gosto da aula. } \\
& \text { EL: Eu tento, sempre. Ainda mais começando do fácil. } \\
& \text { EM: Eu gosto e aqui ninguém cobra perfeição (Grupo Focal II, 07/04/2015). }
\end{aligned}
$$

Considera-se, dessa forma, que mesmo os estudantes que tinham menor engajamento nas vivências práticas evidenciam uma relação positiva com os saberes da Educação Física.

Contudo, por que alguns estudantes não demoram tanto em realizar as atividades? Os indícios levam-me a considerar que tal fato acontece porque são atividades que esses estudantes associam a vivências anteriores, e rapidamente analisam os recursos que possuem e têm uma resposta rápida. Já quando se trata de algo novo para os estudantes essa observação ocorre de forma mais atenta e demorada e o potencial inicial de mobilização depende ainda mais dos recursos disponíveis. Mas quais são esses indícios? Os primeiros estudantes a finalizar as atividades são os que participam de vivências motoras fora da unidade curricular de Educação Física na escola ou fora da escola. Os estudantes mais dinâmicos em relação às vivências participavam das turmas de treinamento e relataram nos questionários a prática de outras atividades físicas fora da escola, como balé, musculação, futsal, dança, ciclismo e caminhada.

Por conseguinte, não é tão simples indicar as razões do agir, por isso os dados apontam "indícios", já que as motivações, de acordo com Gonzalez, Broens e Serzedello (2000), carregam elementos subjetivos que refletem a complexidade da história cultural do sujeito e confundem-se com as razões.

Ao considerar a mobilização como um ato da vontade guiado por razões e propulsionado por motivações, a técnica atua como elemento objetivo de análise, ou seja, como razões de agir nas aulas de Educação Física. Sendo assim, o repertório corporal do estudante - tendo a técnica como um dos elementos integrantes influencia as possibilidades de mobilização. Ou seja, quanto maior for o repertório corporal do estudante, maior será a possibilidade de mobilização para se atingir uma meta como aprender a lutar, dançar, planejar um treinamento, relacionar-se com os amigos, "passar de ano" na disciplina, quer dizer, o resultado que as ações permitem alcançar.

Por fim, os elementos subjetivos, que dizem respeito à história cultural do sujeito (GONZALEZ; HASELAGER, 2002), influenciam as tomadas de decisões de tal forma, que mesmo o estudante possuindo recursos para realizar uma determinada atividade, elementos subjetivos, como a motivação, a coragem, o medo, podem inibir o potencial inicial de mobilização.

\section{CONSIDERAÇÕES FINAIS}

Sendo assim, nesse cenário teórico e metodológico, os resultados do processo permitiram compreender a mobilização, de acordo com Charlot e Debrun, como um processo auto-organizado, identificado na ação por atratores e ruídos, o que levou os envolvidos a direcionarem seus esforços em torno de metas comuns, o que 
caracterizou a mobilização, além de um início do processo de ensino e aprendizagem com problemas ou surpresas que não rompeu ou destruiu o processo, mas permitiu o surgimento de algo novo.

Assim, o processo investigativo apontou a incidência de oito elementos na mobilização dos estudantes: (i) um trabalho iniciado por problemas oriundos de uma necessidade advinda do próprio contexto escolar; (ii) um corte temporal a partir da decisão de incluir o jiu-jítsu nas aulas por meio de um "acordo democrático"; (iii) exercícios de "fácil" execução, que permitiram estimular o estudante a passar do potencial inicial de mobilização para a mobilização, ou pelo menos o envolvimento na aula; (iv) a vivência dos conteúdos em duplas proporcionou o compartilhamento de informações entre os estudantes; ( $v$ ) na prática do jiu-jítsu houve o respeito que os praticantes dos esportes individuais partilham entre si, uma característica das lutas que favorece a mobilização, assim como os miniambientes de aprendizagem; (vi) a ampliação dos conteúdos atendeu necessidades apontadas pelos estudantes ao serem questionados sobre seus gostos e preferências; (vii) o professor como primus inter pares permitiu o estabelecimento de acordos, respeitados pelos estudantes quando elaborados em um processo democrático; e (viii) identificação dos atratores: miniambientes de aprendizagem, elementos externos, uso de recursos tecnológicos nas aulas e nas propostas de avaliações, o próprio conteúdo como "novidade", escolha das atividades a serem aprendidas e simulação de lutas.

Aponta-se também que o aprendizado rivaliza/interage de formas existentes com os diversos saberes, sendo tal interação potencializada em uma ambiência favorável, na qual os elementos presentes em um projeto (DEBRUN, 1996c), como na aula de Educação Física, têm o mesmo poder de decisão e são influenciados e influenciam os atratores.

No decorrer da pesquisa, foi possível perceber que o processo de interação característico de um ambiente auto-organizado (DEBRUN, 1996b), possibilitou a valorização da Educação Física pelos estudantes (importância para a vida, importância para o crescimento como estudante, como elemento de intercâmbio com as coisas fora do ambiente escolar, relação com coisas que já viveu), sendo um elemento objetivo e favorável à mobilização nas aulas, que depende, porém, de fatores como técnica, envolvimento dos diversos elementos (colegas, professores, elementos externos), conteúdo e atuação docente. Tal valorização só é possível por meio de uma reflexão do papel do sujeito no projeto e na sua relação com a Educação Física.

Em conclusão, considera-se que a mobilização foi identificada na medida em que o estudante buscava aprender um conteúdo do qual foi copartícipe em todo o processo de ensino e aprendizagem. Sendo assim, os resultados da investigação científica apontaram o surgimento de atratores e ruídos resultantes da interação entre os envolvidos no processo de ensino e aprendizagem, o que possibilitou o diálogo entre a Educação Física Escolar e a vivacidade da cultura corporal de movimento. 


\section{REFERÊNCIAS}

CHARLOT, Bernard. Da relação com o saber e com a escola entre estudantes de periferia. Cadernos de Pesquisa, n.97, p.47-63, 1996.

CHARLOT, Bernard. Da relação com o saber: elementos para uma teoria. Porto Alegre: Artmed, 2000.

CHARLOT, Bernard. Os jovens e o saber: perspectivas mundiais. Porto Alegre: Artmed, 2001.

CHARLOT, Bernard. Relação com o saber, formação dos professores e globalização: questões para a educação hoje. Porto Alegre: Artmed, 2005.

DEBRUN, Michel. Por que, quando e como é possível falar em auto-organização? In: DEBRUN, Michel; GONZALES, Maria Eunice Quilici; PESSOA JR., Osvaldo (orgs.). Auto-organização: estudos interdisciplinares. Campinas: UNICAMP, 1996a. p. xxxiii-xliii (Coleção CLE, v.18).

DEBRUN, Michel. A ideia da auto-organização. In: DEBRUN, Michel; GONZALES, Maria Eunice Quilici; PESSOA JR., Osvaldo (orgs.). Auto-organização: estudos interdisciplinares. Campinas: UNICAMP, 1996b. p. 3-23 (Coleção CLE, v.18).

DEBRUN, Michel. A dinâmica da auto-organização primária. In: DEBRUN, Michel; GONZALES, Maria Eunice Quilici; PESSOA JÚNIOR, Osvaldo (orgs.). Auto-organização: estudos interdisciplinares. Campinas: UNICAMP, 1996c. p. 25-59. (Coleção CLE, v.18).

GONZALEZ, Maria Eunice Quilici; BROENS, Mariana Claudia; SERZEDELLO, Juliana. Auto-organização, autonomia e identidade pessoal. In: D'OTTAVIANO, Itala M. L.; GONZALEZ, Maria Eunice Quilici (orgs.). Auto-organização: estudos interdisciplinares. Campinas: UNICAMP, 2000. p. 69-81. (Coleção CLE, v.30).

GONZALEZ, Maria Eunice Quilici; HASELAGER, Willem Ferdinand Gerardus. Raciocínio abdutivo, criatividade e auto-organização. Cognitivo - Revista de Filosofia, n. 3, p. 22-31, nov. 2002.

MANZOLLI, Jônatas; GONZALES, Maria Eunice Quilici Gonzales; VERSHURE, Paul. Autoorganização, criatividade e cognição. In: D'OTTAVIANO, Itala M. L.; GONZALES, Maria Eunice Q. Auto-organização: estudos interdisciplinares. Campinas: UNICAMP, Centro de Lógica, Epistemologia e História da Ciência, 2000. p. 105-125.

ROMANINI, Vinicius. Prolegômenos para uma Teoria Semiótica da Auto-Organização. In: BRESCIANI FILHO, E.; D'OTTAVIANO, Itala M. L.; GONZALEZ, Maria Eunice Q.; PELLEGRINI, A.M.; ANDRADE, R.S.C. de (orgs.). Auto-organização: estudos interdisciplinares. Campinas: UNICSMP, 2014. p. 367-405. (Coleção CLE, v. 66).

SCHAEFFER, Renato. Auto-organização na ação humana e o naturalismo esclarecido: o modelo de Michel Debrun. In: D'OTTAVIANO, Itala M. L.; GONZALES, Maria Eunice Q. Auto-organização: estudos interdisciplinares. Campinas: UNICAMP, Centro de Lógica, Epistemologia e História da Ciência, 2000. p. 03-54.

SETTE, Antonio M. Máquina de Brouwer e Auto-Organização. In: DEBRUN, M.; GONZALES, Maria Eunice Q.; PESSOA JÚNIOR, Osvaldo. (orgs.). Auto-organização: estudos interdisciplinares. Campinas: UNICAMP, 1996. p. 77-101. (Coleção CLE, v.18).

SILVEIRA, Lauro Frederico Barbosa da Silveira. Origem do cosmos e auto-organização na obra de Charles Sanders Peirce. In: D'OTTAVIANO, Itala M. L.; GONZALES, Maria Eunice Q. Auto-organização: estudos interdisciplinares. Campinas: UNICAMP, Centro de Lógica, Epistemologia e História da Ciência, 2000. p. 325-336. 
STENHOUSE, Lawrence. La investigación como base de la ensenãnza. 2. ed. Madrid: Morata, 1993.

TRIPP, David. Pesquisa-ação: uma introdução metodológica. Educação e Pesquisa, v. 31, n. 3, p. 443-446, set./dez. 2005. 
Abstract: This research aims to describe and understand the results of an intervention in Physical Education's teaching and learning processes in a self-organized proposal based on Michel Debrun's Theory of Self-Organization. It is an action research study guided by two main questions: Why and for what purpose do students are mobilized or not by contents presented to them? What are the attractors and noise and what roles do they play in teaching and learning processes? The study involved 16 students of the 5th period in a federal secondary-level vocational school. In this scenario, the results of the investigation pointed to the emergence of mobilization as attractors and noises appeared in the teaching and learning process.

Keywords: Physical Education. Learning. Education primary and Secondary.

Resumen: La investigación tiene como objetivo describir y comprender los resultados de una intervención en los procesos de enseñanza y aprendizaje en Educación Física en una propuesta auto-organizada, basada en la Auto-organización de Michel Debrun. Se caracterizó como investigación de acción y se guió por dos preguntas principales: ¿Por qué y para qué se moviliza o no el alumno, frente a los contenidos que se le presentan? ¿Cuáles son los atractores y el ruido, y cuáles son sus roles en el proceso de enseñanza y aprendizaje? Involucró a 16 estudiantes de una escuela técnica federal que asistían al quinto período del curso técnico integrado de la escuela secundaria. En este escenario, los resultados del proceso de investigación apuntaban a la aparición de la movilización como atractores y surgieron ruidos identificados en el proceso de enseñanza y aprendizaje.

Palabras clave: Educación Física. Aprendizaje. Educación primaria y Secundaria. 


\section{LICENÇA DE USO}

Este é um artigo publicado em acesso aberto (Open Access) sob a licença Creative Commons Atribuição 4.0 Internacional (CC BY 4.0), que permite uso, distribuição e reprodução em qualquer meio, desde que o trabalho original seja corretamente citado. Mais informações em: http://creativecommons.org/licenses/by/4.0

\section{CONFLITO DE INTERESSES}

Os autores declararam que não há conflito de interesses neste trabalho.

\section{CONTRIBUIÇÕES AUTORAIS}

Alan Rodrigo Antunes: Contribuição intelectual substancial na concepção do artigo, bem como coleta e análise de dados.

Mauro Betti: Contribuição intelectual e revisão crítica do conteúdo

\section{FINANCIAMENTO}

O presente trabalho foi realizado sem qualquer apoio financeiro.

\section{COMO REFERENCIAR}

ANTUNES, Alan Rodrigo; BETTI, Mauro. Uma vivência auto-organizada na educação física escolar em uma escola de nível médio. Movimento (Porto Alegre), v.26, p. e26085, jan./dez. 2020. Disponível em: https://seer.ufrgs.br/ Movimento/article/view/104275. Acesso em: [dia] [mês abreviado]. [ano]. DOI: https://doi.org/10.22456/1982-8918.104275

\section{RESPONSABILIBADE EDITORIAL}

Alex Branco Fraga*, Elisandro Schultz Wittizorecki*, Ivone Job*, Mauro Myskiw*, Raquel da Silveira*

*Universidade Federal do Rio Grande do Sul, Escola de Educação Física, Fisioterapia e Dança, Porto Alegre, RS, Brasil 